\title{
Deep and methane-rich lakes on Titan
}

\author{
M. Mastrogiuseppe ${ }^{1 *}$, V. Poggiali ${ }^{2}{ }^{2}$, A. G. Hayes ${ }^{2}$, J. I.Lunine' ${ }^{2}$, R. Seu ${ }^{3}$, G. Mitri ${ }^{4}{ }^{4}$ and R. D. Lorenz ${ }^{5}$
}

Saturn's largest moon, Titan, hosts liquid hydrocarbon lakes and seas on its surface. During the last close encounter with Titan (22 April 2017), the Cassini spacecraft used its RADAR as a sounder to probe the depth of several lakes in the north polar terrain. This was the first time that Titan's lakes, as opposed to its seas, have been viewed in a sounding configuration. Here, we show that these lakes can exceed $100 \mathrm{~m}$ depth and their transparency at the $2.17 \mathrm{~cm}$ radar wavelength indicates that they have a methane-dominated composition. This composition differs significantly from that of Ontario Lacus, the only major lake in Titan's southern hemisphere, which is more ethane rich. If the methane-rich north polar lakes, perched hundreds of metres above the major seas, are formed by a karstic-type process, then they may drain by subsurface flow at rates between 0.001 and $1 \mathrm{~m} \mathrm{yr}^{-1}$ (Titan year). Subsurface reservoirs and flows therefore may be an important element of the Titan geochemical system.

D uring its 13 years (2004-2017) tour of the Saturnian system, the multimode RADAR instrument onboard the Cassini spacecraft ${ }^{1}$ mapped hundreds of lakes and three large seas located in the northern hemisphere of Saturn's largest moon, Titan ${ }^{2,3}$ (Fig. 1). The presence of these basins has been identified as a strong evidence for a methane-based hydrological cycle taking place on the surface and in the atmosphere of the moon ${ }^{4,5}$.

Distributed over an area of $7 \times 10^{5} \mathrm{~km}^{2}$ (ref. ${ }^{8}$ ), Titan's north polar lakes show varying brightness in synthetic aperture radar (SAR) images and are characterized by circular-elongated basin/depressions, often encompassed by raised rims ${ }^{7}$. Inflow and outflow channels are not visible at the SAR image resolution $(\sim 300 \mathrm{~m})$. Unless the depressions are connected by unresolved (and thus narrow) but nonetheless extensive channels, this implies that the removal of material occurs by means of processes like sublimation or dissolution followed by subsurface transport ${ }^{3,7}$. Reference ${ }^{9}$ interpreted the topography of Titan's lakes as the effect of karstic dissolution processes acting on the surface, although the nature of their raised rims remains unknown.

Specific observations performed by the Cassini RADAR instrument in altimetry mode ${ }^{1}$ allowed the determination of the depth and composition of some of the largest liquid bodies, such as Ligeia Mare, Punga Mare and Ontario Lacus ${ }^{10-13}$. The success of these observations led to a similar measurement being planned and executed for northern hemisphere lakes during the last flyby of Cassini.

\section{Results}

Cassini's last flyby of Titan (T126) occurred on 22 April 2017 and had a nadir ground track that passed over several lakes varying from 10 to $50 \mathrm{~km}$ in diameter (Fig. 2). The T126 flyby allowed the RADAR to observe these lakes in altimetry mode, acquiring 211 bursts of data at nadir (incidence angles $<0.08 \mathrm{deg}$ ) along $450 \mathrm{~km}$ of ground track from an altitude ranging between 1,080 and $1,280 \mathrm{~km}$.

The altimetric profile obtained using conventional processing ${ }^{14}$ and the relative radar cross-section are shown in Fig. 2b,c. Abrupt changes in radar cross-section (Fig. 2c) are indicative of the sudden transition between smooth liquid and solid surfaces. The analysis of altimetry data along with SAR images suggests that the footprint intercepted seven lakes (hereafter indicated with letters from
A to G) surrounded by terrain characterized by 100 -m-scale topographic variability (Fig. 2b).

Right after the transition between SAR and altimeter modes, the footprint intercepted the first lake: Oneida Lacus (lake A), located at $76^{\circ} \mathrm{N}, 135^{\circ} \mathrm{W}$. Oneida Lacus was only partially observed along $15 \mathrm{~km}$ of track but it appears to be the darkest in SAR images, likely because of its extreme depths. Successively, other lacustrine features have been observed. A few tens of kilometres from Oneida, a bright lake (lake B) and an 'S'-shaped lake (lake C) at about $76.5^{\circ} \mathrm{N}, 135^{\circ} \mathrm{W}$ and $77^{\circ} \mathrm{N}, 140^{\circ} \mathrm{W}$, respectively, have been observed, followed by a small lake (lake D) where only two echoes have been acquired over the liquid. Successively, a 'seahorse'-shaped lake (lake E or Winnipeg Lacus) located roughly at $78^{\circ} \mathrm{N}, 155^{\circ} \mathrm{W}$ was observed for about $20 \mathrm{~km}$ of track and finally data were acquired for lakes $\mathrm{F}$ and G located at $78.5^{\circ} \mathrm{N}, 160^{\circ} \mathrm{W}$ and $78.5^{\circ} \mathrm{N}, 165^{\circ} \mathrm{W}$, respectively, over which the antenna footprint illuminated a region where both liquid and the solid surfaces were present.

We used super-resolution algorithms previously applied to radar data acquired over Ligeia Mare, Punga Mare and Ontario Lacus ${ }^{10-13}$ to enhance radar range resolution ${ }^{15}$ and improve bathymetric detection capabilities. The results of the processing revealed a clear detection of the floor of lake $\mathrm{E}$ along $20 \mathrm{~km}$ of radar transect, in addition to the echoes reflected from the surface of the lake. Figure $3 \mathrm{c}$ depicts the bathymetry of lake $\mathrm{E}$, which reaches a maximum depth of $105 \pm 6 \mathrm{~m}(1 \sigma)$ and appears to have an asymmetric lakebed with a relatively gentle slope (about $0.16^{\circ} \pm 0.03^{\circ}$ ) towards the east and a sharp rise on the western side. This could represent the stepped topography observed in empty lake basins which, along with other morphometric indications ${ }^{7}$, can be interpreted as evidence for basin agglomeration through scarp retreat.

Applying the method as described in ref. ${ }^{10}$, a liquid attenuation of $17 \pm 7 \mathrm{~dB} \mathrm{\mu s}^{-1}$ (corresponding to a loss tangent equal to $\left.4.6 \pm 1.8 \times 10^{-5}\right)$ is estimated from the ratio of surface to subsurface power $\left(P_{s} / P_{s s}\right)$ as a function of increasing depth (Fig. 3e). We found that, similar to Ligeia Mare, the attenuation of Winnipeg Lacus requires a methane-nitrogen dominated composition (best fit values of $69 \% \mathrm{CH}_{4}, 15 \% \mathrm{C}_{2} \mathrm{H}_{6}$ and $16 \% \mathrm{~N}_{2}$ and $1 \sigma$ error values of 54-80\% $\mathrm{CH}_{4}, 35-0 \% \mathrm{C}_{2} \mathrm{H}_{6}$ and 11-20\% $\mathrm{N}_{2}$ in volume) to match laboratory measurements of hydrocarbon loss tangents ${ }^{16}$. If a significant fraction (> 50\%) of ethane or higher-order components

'Division of Geological and Planetary Sciences, California Institute of Technology, Pasadena, CA, USA. 'Department of Astronomy, Cornell University, Ithaca, NY, USA. 'University of Rome 'La Sapienza', Rome, Italy. ${ }^{4}$ International Research School of Planetary Sciences, Università d'Annunzio, Pescara, Italy. 5Johns Hopkins University Applied Physics Laboratory, Laurel, MD, USA. *e-mail: mmastrog@caltech.edu 
a

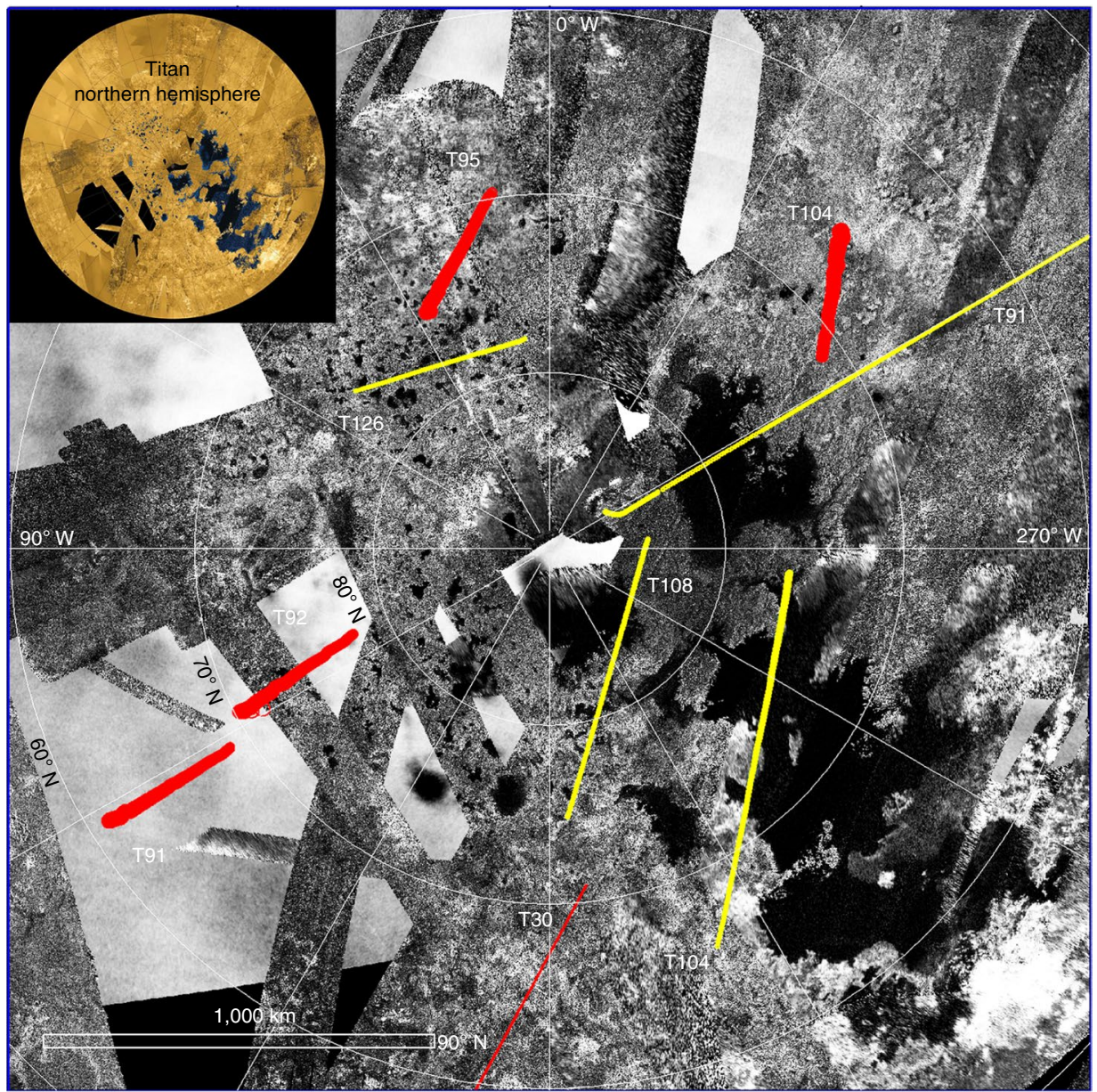

b

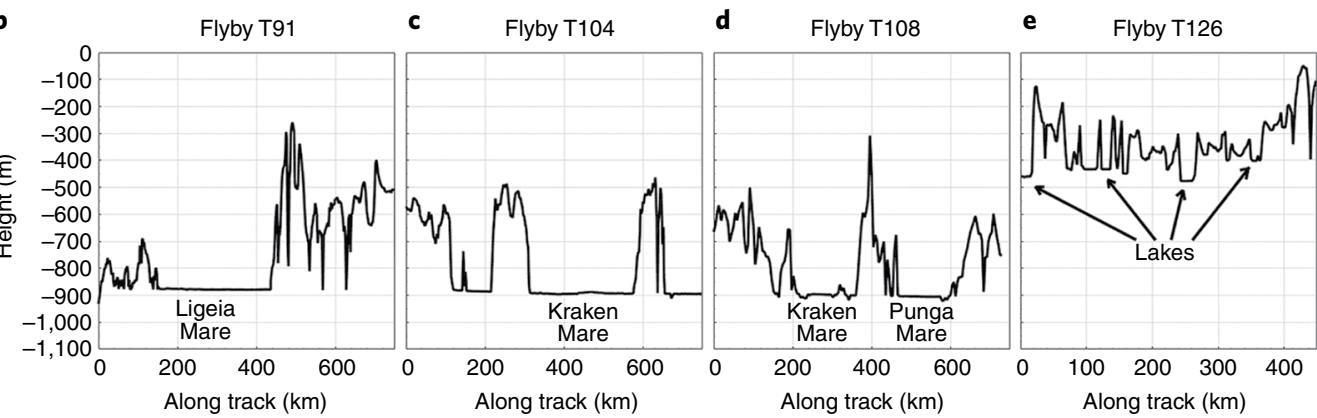

Fig. 1 | Cassini RADAR image mosaic and altimetry tracks acquired during the Cassini mission on the norther polar region of Titan. a, SAR mosaic and relative altimetric tracks (red and yellow lines) acquired at the northern polar terrain during the Cassini mission. The ground tracks of the altimetric profiles reported in $\mathbf{b}$-e are shown in yellow. The inset mosaic shows the location of lakes and seas in the northern hemisphere of Titan. $\mathbf{b}-\mathbf{e}$, Altimetric profiles relative to Titan's 2,575 km sphere, obtained from flybys T91, T104, T108 and T126, respectively. The lakes' liquid level (flyby T126) is about $400 \mathrm{~m}$ above the sea level (flybys T91, T104, T108). Note that the heights reported here are not tied down to the topographic network of ref. ${ }^{6}$ and so are offset from the liquid-level elevations reported in ref. ${ }^{7}$.

(for example, propane) were present, the attenuation would have been greater than the one observed and able to suppress the subsurface returns (see Supplementary Fig. 1).

The result of the altimeter processing applied to lakes $\mathrm{A}$ and $\mathrm{C}$ is presented in Fig. 4. The radargrams obtained from the S-shaped lake (lake C) are shown in Fig. 4e,f. Although we applied super-resolution techniques to this dataset, echoes received from the lakefloor are difficult to separate from the specular echoes generated at the surface. Figure $4 \mathrm{~h}, \mathrm{i}$ shows examples of waveforms acquired at about $140.17^{\circ}$ and $142.64^{\circ}$ in longitude over lake C. These waveforms indicate that the deepest portion measured along the track is approximately $30-40 \mathrm{~m}$, which is consistent with the increased brightness recorded by SAR images, indicating a shallow basin (see Fig. 4).

In general, we found that SAR backscatter is correlated with depth measurements derived from sounding. In other words, darker lakes appear darker because they are deeper and not because they have significantly different compositions from the brighter lakes observed.

Also, Fig. 4 shows the SAR image of Oneida Lacus (lake A; Fig. 4a), the relative radargram (Fig. 4d) and a waveform (Fig. 4g). 

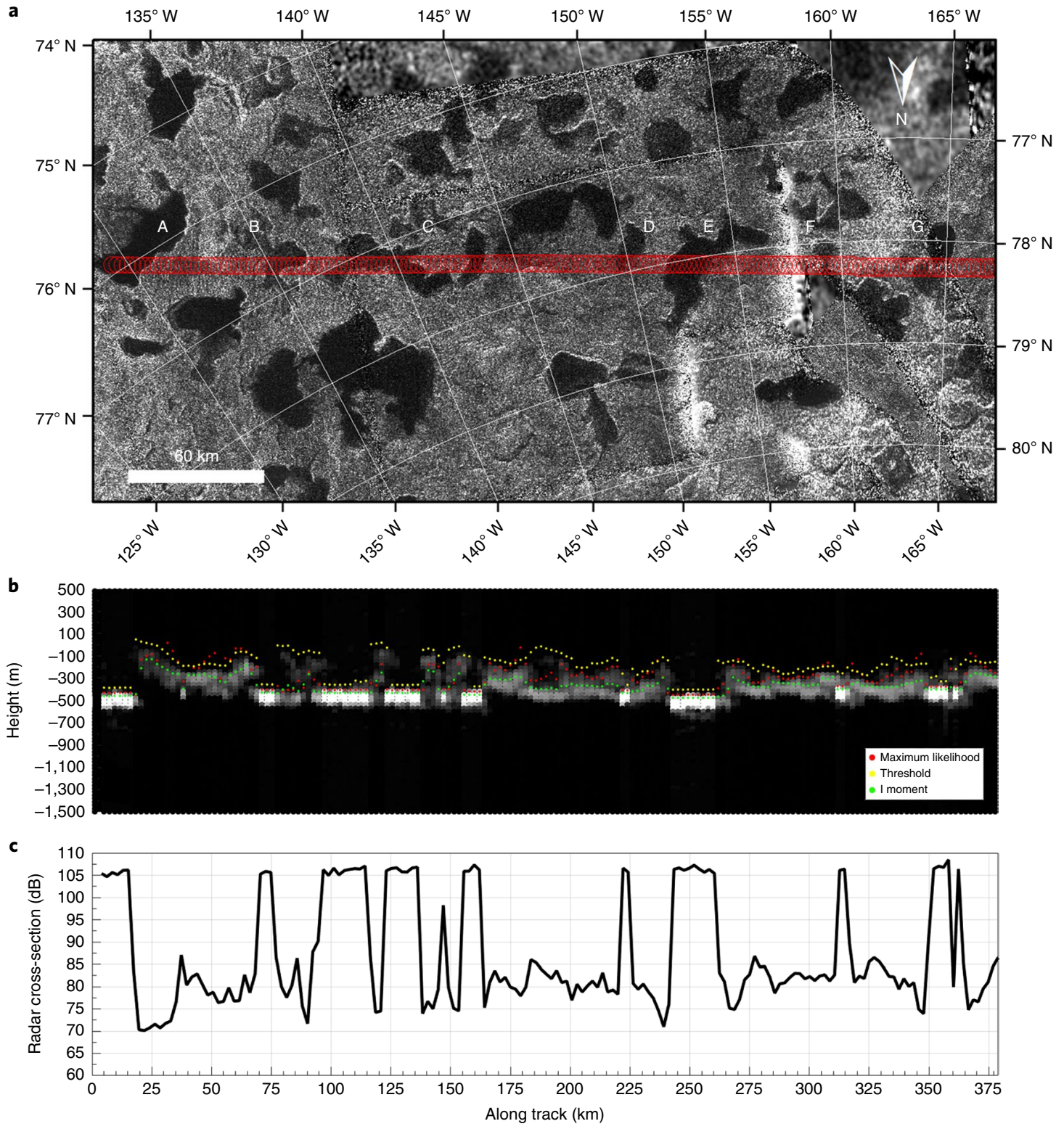

Fig. 2 | Intercepted lakes from radar altimetry on T126 flyby. a, Radar image mosaic with overplotted relative outbound altimetric ground track of flyby T126 with red circles indicating footprints at $-3 \mathrm{~dB}$ antenna gain and the letters A-G marking the locations of the lakes intercepted by the ground track. b, Radargram and altimetric profiles relative to Titan's $2,575 \mathrm{~km}$ sphere obtained using different tracking methods (I moment, threshold, maximum likelihood). The white and grey shading of the radargram indicates differences in radar cross-section. c, Radar cross-section of T126 flyby. The abrupt changes to very high values of cross-section indicate the presence of exposed smooth liquid intercepted by the radar. Note that the heights reported here are not tied down to the topographic network of ref. ${ }^{6}$, and so are offset from the liquid-level elevations reported in ref. ${ }^{7}$.

The waveforms fail to show unambiguous evidence for a continuous lakefloor, although a few echoes received just above the noise level indicate that the lakefloor depths are greater than $150 \mathrm{~m}$, which is consistent with the darkness of the lake as it appears in SAR images.

For lakes B, D, F and G, the antenna footprint intercepted both liquid and solid surface close to the shoreline of the lakes, making radar measurements ambiguous and challenging (Supplementary Fig. 2).

Along the $450 \mathrm{~km}$ observation that stretches over this region, the radar altimeter did not detect any additional specular reflection from smaller liquid bodies such as the liquid-filled channels detected on T $91{ }^{17}$ or smaller lakes/ponds similar in size to the Fresnel area (about $4 \times 10^{4} \mathrm{~m}^{2}$ ). Note that the altimeter is very sensitive to any presence of smooth liquid surfaces on Titan with an extent comparable to the Fresnel diameter ( $200 \mathrm{~m}$ at $1,000 \mathrm{~km}$ of altitude). While this doesn't exclude the possible presence of any small rivers nearby lakes, it suggests that major fluvial features are not present and transport of the liquids should occur via subsurface flow rather than surface inflow and outflow.

In addition to the analysis of depth/composition of each individual lake, we investigated the surface backscattering of all the observed lakes (see Methods). These values were then compared with those acquired during the T91 flyby over Ligeia Mare. Similar analysis of the backscattering of Ligeia Mare, but not the lakes, is reported in ref. ${ }^{18}$. We found that all the lakes (distributed along more than $350 \mathrm{~km}$ of track) have very similar backscattering compared to Ligeia Mare (Fig. 5). In addition, values (average $=33.4 \pm 0.5 \mathrm{~dB}$ 
$\mathbf{a}$

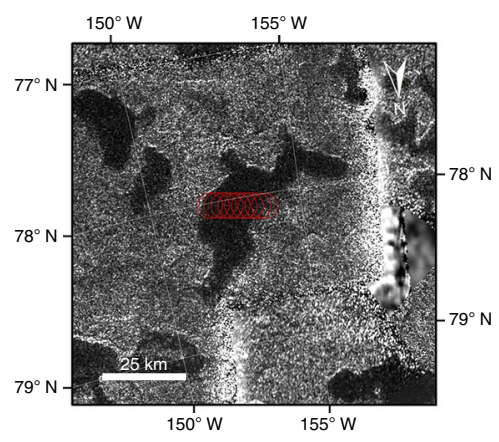

b

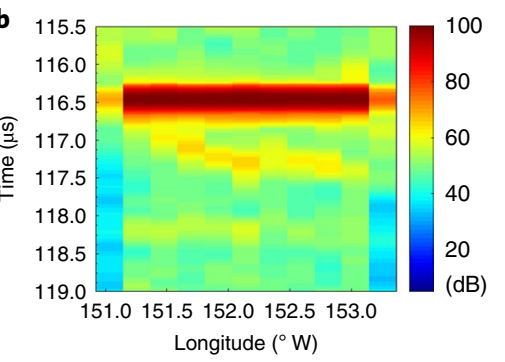

c

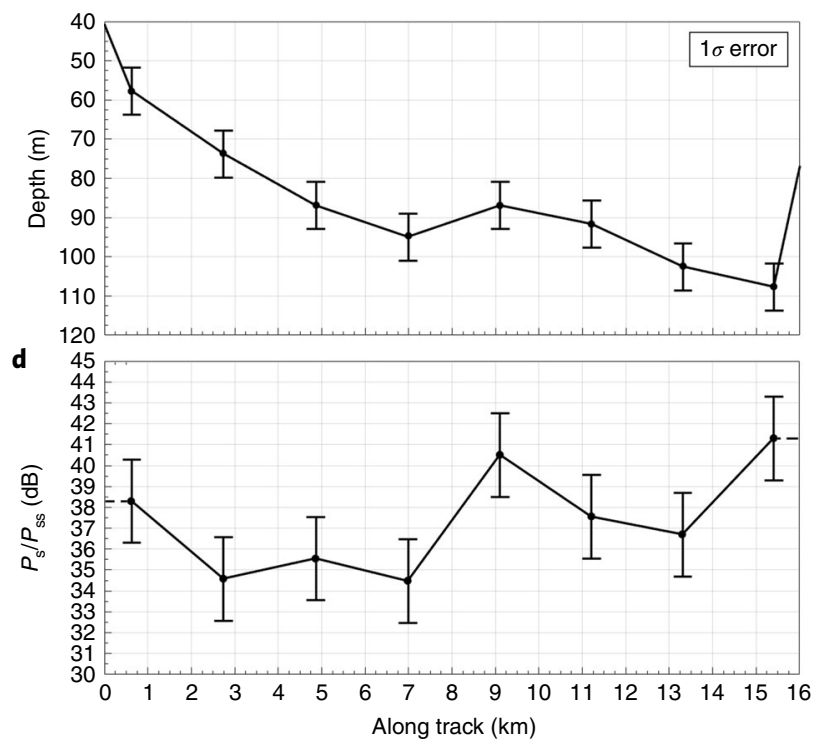

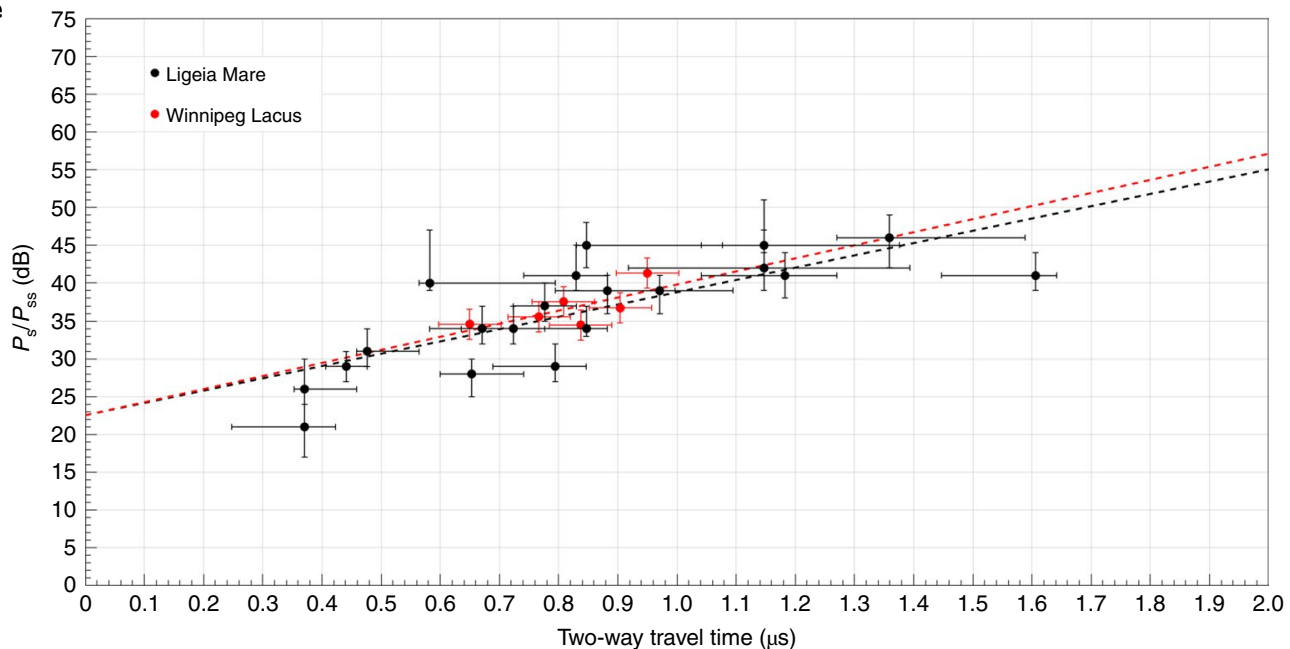

Fig. 3 | Bathymetry and liquid attenuation of Winnipeg Lacus. a, SAR mosaic showing Winnipeg Lacus and the location of the -3 dB beam-limited altimeter footprints over liquid (red circles). b, Radargram obtained after super-resolution processing (see details in Methods). c,d, Bathymetry (c) and relative surface-subsurface echoes intensity ratio $\left(P_{\mathrm{s}} / P_{\mathrm{ss}}\right)$ values $(\mathbf{d})$ measured over Winnipeg. Error bars are relative to $1 \sigma$ uncertainness. e, Estimation of specific attenuation of the liquid in Winnipeg Lacus is $17 \pm 7 \mathrm{~dB}_{\mu} \mathrm{s}^{-1}$ (best fit of a loss tangent equal to $4.6 \times 10^{-5}$ ), where for Ligeia Mare we obtained

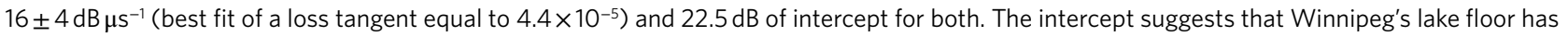
similar backscattering values when compared to Ligeia's seafloor, which is indicative of similar composition. Errors reported here are at $1 \sigma$ and have been calculated using a Monte Carlo approach (see Methods).

for T126 versus $32.9 \pm 0.5 \mathrm{~dB}$ for T91) are extremely stable (see Supplementary Table 1).

This finding suggests that Titan lakes are similar in composition and characterized by a quite smooth surface (height standard deviation $<2 \mathrm{~mm}$ waves), as previously observed over Ligeia Mare when compared with the other basins ${ }^{18,19}$. Note that the difference in reflectivity between pure methane and ethane is greater than $2 \mathrm{~dB}$ while the standard deviation of backscattering measured on the lakes is less than $1 \mathrm{~dB}$. This excludes any substantial variation of the liquid composition among lakes, as well as any significant variation of the roughness or presence of any transient features ${ }^{20}$ as observed over Ligeia Mare during flyby T $92^{21}$.

The radar waveforms also show similarities when compared to those acquired over Ligeia Mare at the same depths during flyby T91 ${ }^{10}$. Figure 6 shows an example of two radar waveforms acquired when the seafloor was at depths around $75 \mathrm{~m}$ and $90 \mathrm{~m}$, over Winnipeg Lacus and North Ligeia Mare. Both radar shape and amplitudes are similar, indicating that in addition to the liquid composition and roughness, the floors of these basins are similar and composed, most probably, of compacted organic material resulting from a deposition process ${ }^{22}$. Nonetheless, we cannot exclude the possible presence of water ice as inferred elsewhere on Titan from radiometric measurements ${ }^{23}$.

\section{Discussion}

The detection of 100-m-deep lakes presenting a methane-dominated composition constrains the formation, evolution and present state of lacustrine basins in Titan's north polar terrain. 

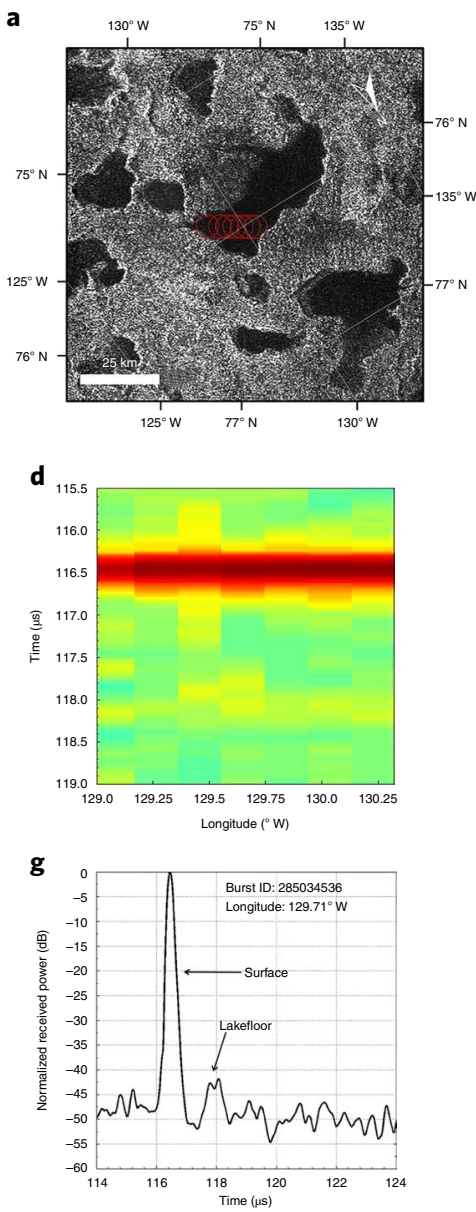

b
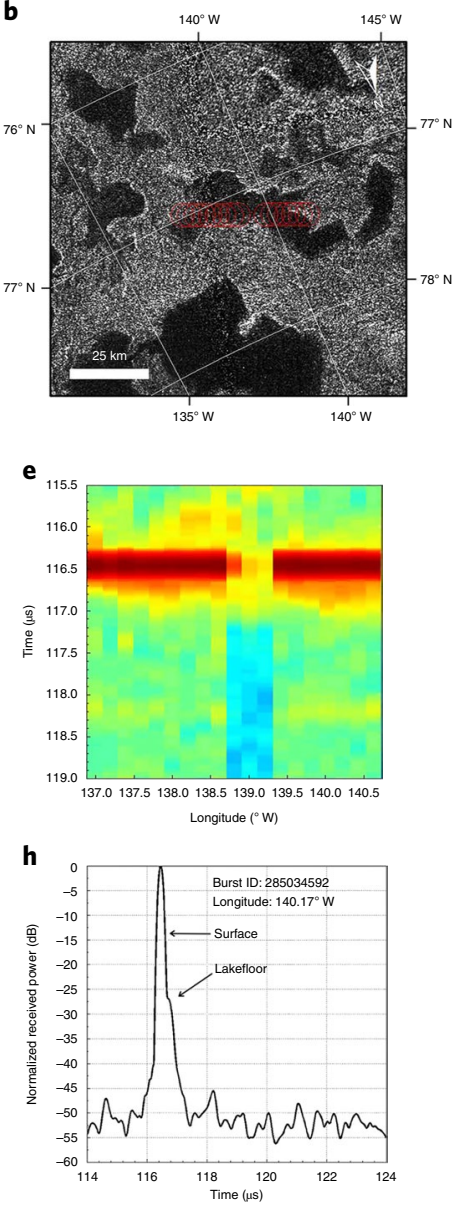

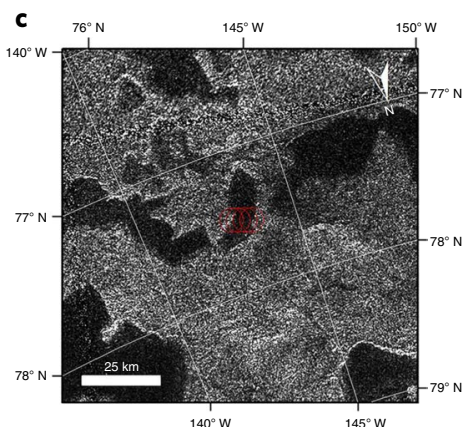

$\mathbf{f}$

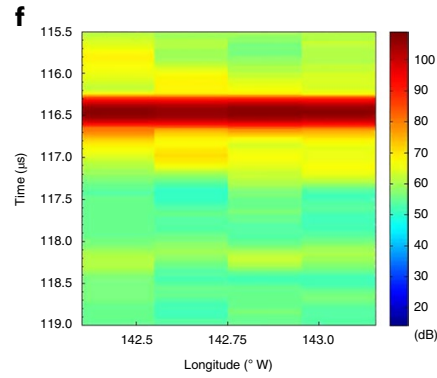

i

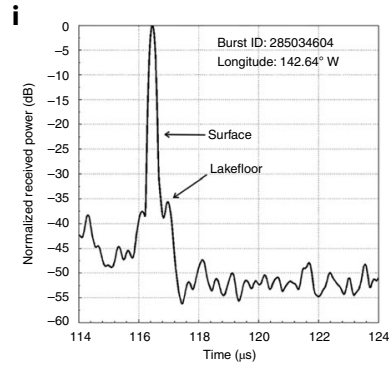

Fig. 4 | Ambiguous lakefloor detections of Oneida Lacus and lake C. Ambiguous detections happen when waveforms do not show clear subsurface returns due to low signal-to-noise ratio (SNR) or radar resolution. a-c, SAR mosaics and -3 dB beam-limited altimeter footprints (red circles) over liquid for Oneida Lacus, and the east and west parts of lake C, respectively. d-f, Super-resolved radargrams of the same lakes and portion of lake. $\mathbf{g}$, A waveform acquired over the central portion of Oneida. Detection of the lakefloor is ambiguous due to the low SNR. Some echoes suggest depths greater than $150 \mathrm{~m}$. $\mathbf{h , i}$, Waveforms acquired over the S-shaped lake or lake $\mathrm{C}$ show subsurface returns not or partially resolved by super-resolution algorithms.

These waveforms indicate that observed regions are shallow, with depths not exceeding 20-30 m.
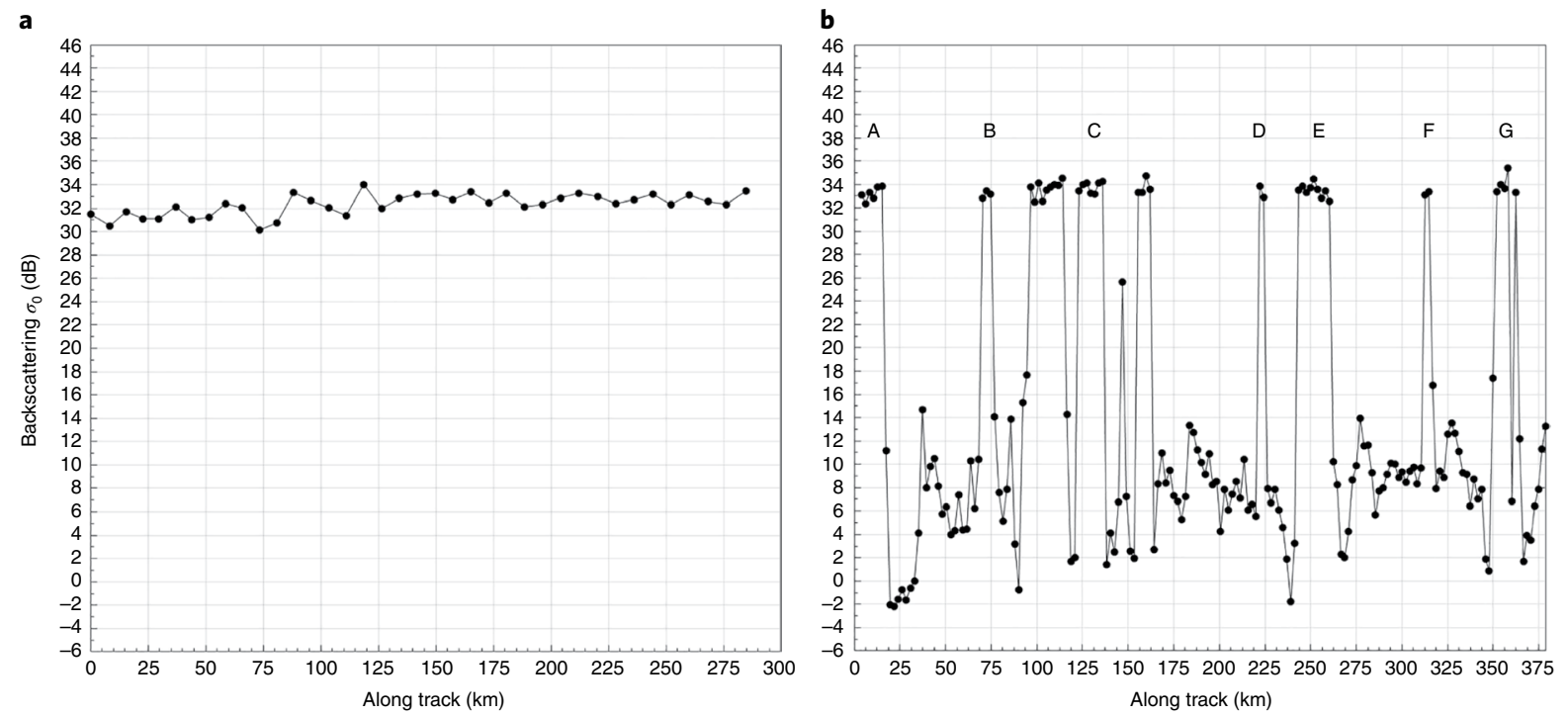

Fig. 5 | Comparison of Ligeia Mare and lake surface backscattering during flyby T91 (23 May 2013) and T126 (22 April 2017). a,b, Comparison between the surface backscattering obtained from the Ligeia Mare (a) and lakes A-G observed during the flyby T126 (b). Values have been obtained using the coherent scattering formula as described in Methods. The similarity and the stability of measurements of Ligeia and lakes along hundreds of kilometres of tracks is indicative of a similar methane-dominated composition and no significant variations of roughness at the time of observation. 
a

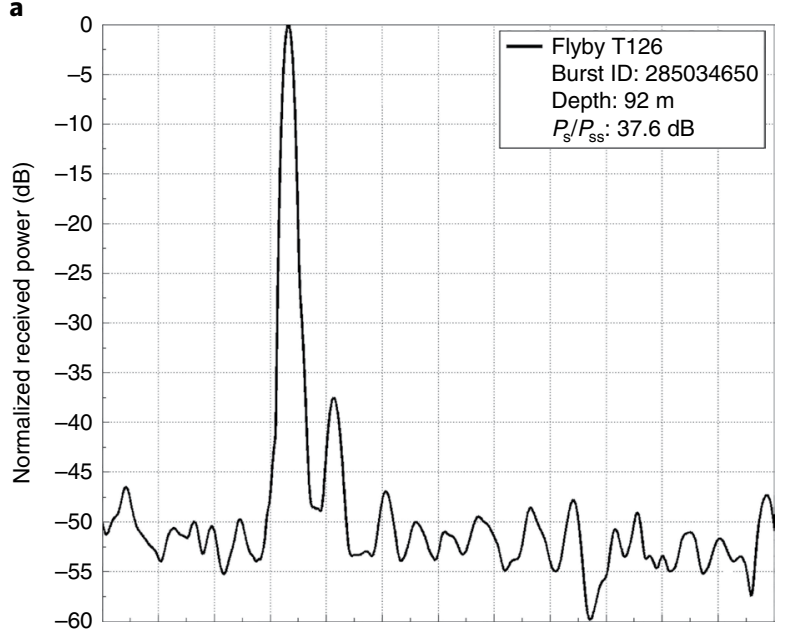

b

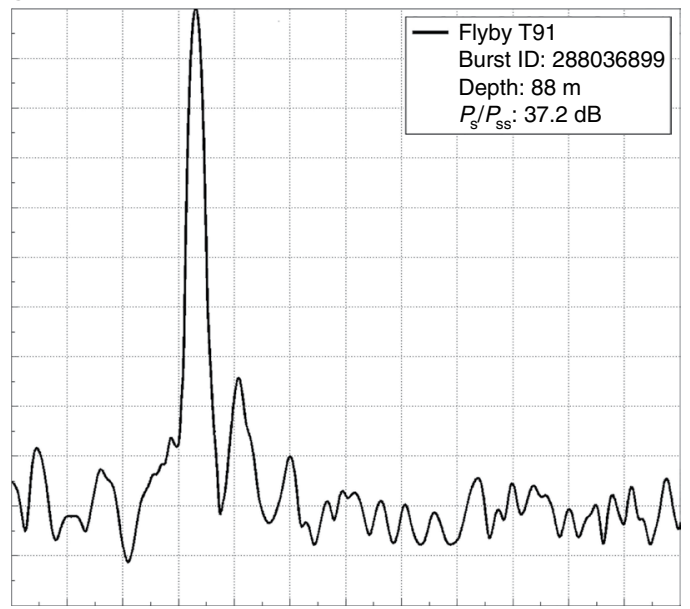

C

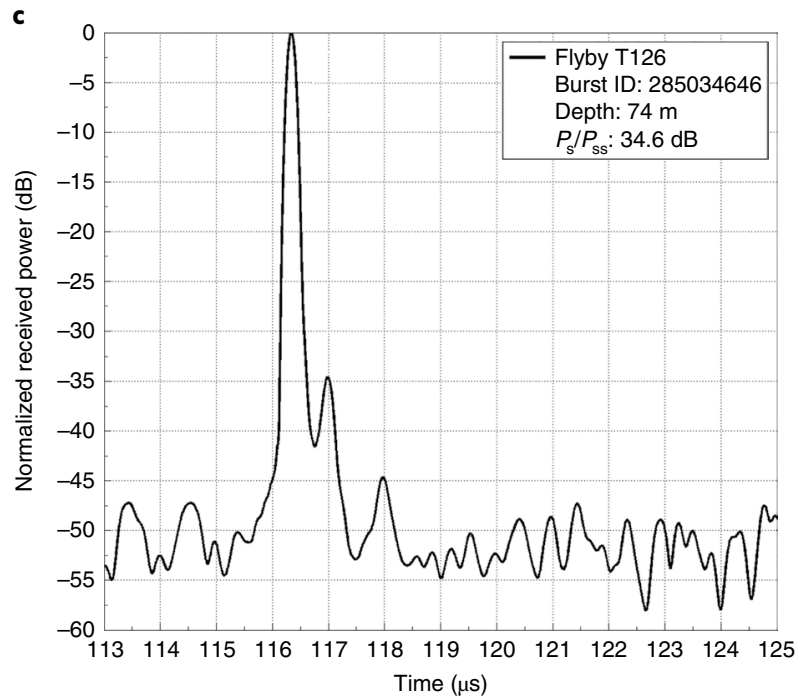

d

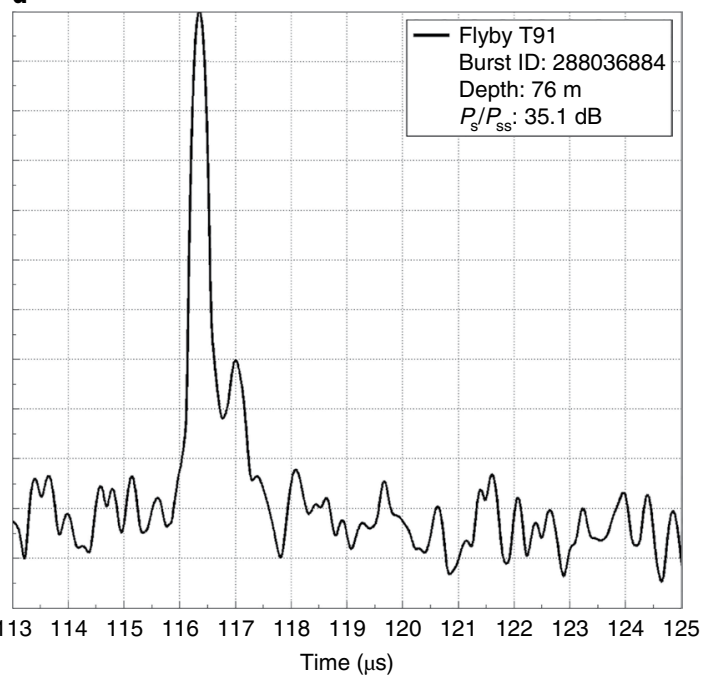

Fig. 6 | Ligeia Mare and Winnipeg Lacus waveforms acquired at similar depths. a,b, Waveforms acquired at about $90 \mathrm{~m}$ depth. c,d, Waveforms acquired at about $75 \mathrm{~m}$ depth. Note that waveforms appear similar in shape and intensity indicating similarity in liquid composition and subsurface floor.

The measurements here show that these lakes, like others in the northern polar region distal from the larger seas, have liquid surface heights hundreds of metres above the sea level (Fig. 1c). Thus, they are 'perched' and likely fed by local rainfall. They cannot be replenished via subsurface flow from equatorward latitudes (for example, the midlatitude subsurface methane reservoir inferred from global cloud pattern ${ }^{24}$ ). The limiting timescale for the present situation may be the $10^{5}$ year Croll-Milankovich cycles in insolation driven by Saturn's apsidal precession ${ }^{25}$, which may cause periodic desiccation of each pole. A rainfall origin that is regional to the lakes area ${ }^{26}$, and recent if compared with the $10^{5}$ year insolation cycle, is consistent with the methanerich composition we have observed. This composition, likely indicating that the northern lakes are accumulating in volume, is distinct from that of the only other measured lake in the south, Ontario Lacus, which is more ethane rich $^{12}$, surrounded by evaporite deposits ${ }^{27,28}$, and appears to be the vestige of a much larger lake ${ }^{8}$.

A karstic formation process for the lake depressions has been proposed $^{7,9,29}$. While water ice cannot be dissolved to any significant extent by liquid methane and/or ethane ${ }^{30}$, solid organics can, and much of Titan's observable surface appears to be organic rich (for example, ref. ${ }^{23}$ ). In particular, benzene ${ }^{31}$ and acetylene ${ }^{32}$ are soluble in liquid ethane at $94 \mathrm{~K}$ at values comparable to the dissolution of calcium-based minerals in terrestrial seawater. Although solubilities are lower in methane than ethane, dissolution rates even in methane rainfall are fast enough to form $>100 \mathrm{~m}$ depressions in a few tens to hundreds of million years?.

For a karstic formation to work, the liquid must drain away to remove the dissolved material-the deep lake depressions largely preclude surface flow from doing this locally, a few deep canyons notwithstanding, (for example, ref. ${ }^{17}$ ). The 'groundwater' drain, from the lakes we have observed here towards the seas, must be fast enough to have flushed away any ethane or other solutes ${ }^{33}$ in one climate cycle (thus, 0.01-0.001 $\mathrm{m} \mathrm{yr}^{-1}$ ), otherwise we would observe more absorption in the liquid. It must also be slow enough that the lakes do not lose methane faster than it rains in (that is $<\sim 1 \mathrm{~m} \mathrm{yr}^{-1}$ averaged over the Titan year), otherwise these lakes would not be liquid-filled. If indeed subsurface liquid transport occurs on Titan, it might play a significant role in exposing ethane to subsurface water ice, hence sequestering the surprisingly under-abundant alkane by clathration (for example, ref. ${ }^{34}$ ).

\section{Methods}

We processed the T126 Long Burst Data Record using the standard Cassini Processing of Altimetric Data ${ }^{14}$ to generate altimetric profiles and radargrams in Figs. 1 and 2. Altimetric profiles plotted over the radargram are available at 
the Planetary Data System (PDS) node and have been generated using I moment (first moment), threshold and maximum likelihood height trackers as described in refs. ${ }^{35-37}$. Compressed waveforms in complex format are further processed to increase range resolution capabilities using an autoregressive method as described in ref. ${ }^{15}$. Specifically, each pulse within the burst is transformed in frequency domain and the bandwidth is extrapolated by a factor of four, using coefficients estimated by means of the Burg's maximum entropy method ${ }^{15}$. The extrapolated bandwidth is tapered using a Blackman function, with an effective improvement in resolution of $\sim 3$ and suppression of side lobes over $-50 \mathrm{~dB}$. The processed echoes are incoherently averaged, and the resulting waveform is used to generate radargrams in Figs. 3 and 4 and echoes in Fig. 6. The SAR images we used are standard products available at the PDS node and processed with noise subtraction and incidence angle correction.

Bathymetric measurements have been performed using the following formula: depth $=\Delta \tau c /(2 n)$, where $\Delta \tau$ is the two-way travel time measured at surface and subsurface echo peaks, $c$ is the speed of light in vacuum and $n$ is the index refraction. In this work, the adopted value of $n$ is $1.32\left(n=\sqrt{ } \varepsilon_{\mathrm{r}}\right.$, with the real part of the dielectric constant $\left.\varepsilon_{\mathrm{r}}=1.75\right)$, which is determined from mixture models and the loss tangent as estimated from $P_{s} / P_{\mathrm{ss}}$ and $\Delta \tau$ measurements.

Bathymetric uncertainties have been evaluated similarly to ref. ${ }^{10}$ where a second-order polynomial function is fitted over the floor profile. Note that the knowledge of the effective dielectric constant of the liquid, obtained from our loss tangent estimation, results in index refraction uncertainties having a negligible impact on the overall uncertainties of the depth measurements. Assuming a minimum value for the real part of dielectric constant be equal to pure methane $\left(\varepsilon_{\mathrm{r}}=1.7\right.$ or $\left.n=1.3\right)$ and a maximum value equal to $50 \%$ of ethane $\left(\varepsilon_{\mathrm{r}}=1.9\right.$ or $n=1.38)$, the maximum variation in depths will be few percentage points only.

Uncertainties of the lakefloor slope $\left(0.16^{\circ} \pm 0.03^{\circ}\right)$ are obtained using Monte Carlo along with the uncertainties of depths.

The surface power versus subsurface power ratio $\left(P_{\mathrm{s}} / P_{\mathrm{ss}}\right)$ recorded at increasing depths is used to investigate the liquid attenuation and retrieve the loss tangent of the media as described in ref. ${ }^{10}$. Uncertainties of the loss tangent estimation have been evaluated using a Monte Carlo approach, where the uncertainties of the surface versus subsurface power $\left(P_{s} / P_{\mathrm{ss}}\right)$ have been evaluated ( $1 \sigma$ error) after compensation of the column attenuation $K$, and under the assumption of lakefloor uniformity (that is, no significant spatial variation of the lakefloor dielectric properties and roughness). The uncertainties in the liquid composition is derived from loss tangent errors using ${ }^{16}$ and mixture models ${ }^{38}$.

Supplementary Fig. 1 shows three simulations performed using a two-layers model as described in ref. ${ }^{39}$ for three different values of loss tangent equal to $3.3 \times 10^{-5}$ (no ethane), $4.6 \times 10^{-5}$ (estimated value of $17 \%$ of ethane) and $8 \times 10^{-5}$ ( $50 \%$ of ethane). Each radargram is simulated using the estimated depths of Winnipeg Lacus and a real component of the relative dielectric constant equal to 1.7 for the liquid and 2 for the solid lakefloor.

Backscattering values have been obtained by scaling the beam-limited area calculated at $-3 \mathrm{~dB}$ to the radar cross-section and considering off-nadir angle effects as described in ref. ${ }^{40}$. The curvature of the planet has been taken into account using equation (8) in ref. ${ }^{41}$.

\section{Data availability}

The data that support the plots within this paper and other findings of this study are available from the corresponding author upon reasonable request. Long Burst Data Record products are available from NASA Planetary Data System (https:// pds-imaging.jpl.nasa.gov/data/cassini/cassini_orbiter).

Received: 9 August 2018; Accepted: 30 January 2019; Published online: 15 April 2019

\section{References}

1. Elachi, C. et al. Radar: the Cassini Titan radar mapper. Space Sci. Rev. 115, 71-110 (2004)

2. Stofan, E. R. et al. The lakes of Titan. Nature 445, 61-64 (2007)

3. Hayes, A. G. et al. Hydrocarbon lakes on Titan: distribution and interaction with a porous regolith. Geophys. Res. Lett. 35, L09204 (2008).

4. Hayes, A. G. The lakes and seas of titan. Annu. Rev. Earth Space Sci. 44, 57-83 (2016).

5. Hayes, A. G., Lorenz, R. D. \& Lunine, J. I. A post Cassini view of Titan's methane-based hydrologic cycle. Nat. Geosci. 11, 306-313 (2018).

6. Corlies, P. et al. Titan's topography and shape at the end of the Cassini mission. Geophys. Res. Lett. 44, 11754-11761 (2017).

7. Hayes, A. G. et al. Topographic constraints on the evolution and connectivity of Titan's lacustrine basins. Geophys. Res. Lett. 44, 11745-11753 (2017).

8. Birch, S. P. D. et al. Geomorphologic mapping of titan's polar terrains: Constraining surface processes and landscape evolution. Icarus $\mathbf{2 8 2}$, 214-236 (2017).

9. Cornet, T. et al. Dissolution on titan and on Earth: toward the age of Titan's karstic landscapes. J. Geophys. Res. Planets 120, 1044-1074 (2015).
10. Mastrogiuseppe, M. et al. The bathymetry of a Titan sea. Geophys. Res. Lett. 41, 1432-1437 (2014)

11. Mastrogiuseppe, M. et al. Radar sounding using the Cassini altimeter: waveform modeling and Monte Carlo approach for data inversion of observations of Titan's seas. IEEE Trans. Geosci. Remote Sens. 54, 5646-5656 (2016)

12. Mastrogiuseppe, M. et al. Bathymetry and composition of Titan's Ontario Lacus derived from Monte Carlo-based waveform inversion of Cassini RADAR altimetry data. Icarus 300, 203-209 (2018).

13. Mastrogiuseppe, M. et al. Cassini radar observation of Punga Mare and environs: bathymetry and composition. Earth Planet. Sci. Lett. 496, 89-95 (2018).

14. Alberti, G. et al. The processing of altimetric data (PAD) system for Cassini RADAR. Mem. Soc. Astron. Ital. Suppl. 11, 68 (2007).

15. Raguso, M. C., Mastrogiuseppe, M., Seu, R. \& Piazzo, L. Super resolution and interferences suppression technique applied to SHARAD data. In 5th IEEE Int. Workshop Metrology for AeroSpace 242-246 (IEEE, 2018).

16. Mitchell, K. L., Barmatz, M. B., Jamieson, C. S., Lorenz, R. D. \& Lunine, J. I. Laboratory measurements of cryogenic liquid alkane microwave absorptivity and implications for the composition of Ligeia Mare, Titan. Geophys. Res. Lett. 42, 1340-1345 (2015).

17. Poggiali, V. et al. Liquid-filled canyons on Titan. Geophys. Res. Lett. 43 , 7887-7894 (2016).

18. Zebker, H. et al. Surface of Ligeia Mare, Titan, from Cassini altimeter and radiometer analysis. Geophys. Res. Lett. 41, 308-313 (2014).

19. Grima, C. et al. Surface roughness of Titan's hydrocarbon seas. Earth Planet. Sci. Lett. 474, 20-24 (2017).

20. Hayes, A. G. et al. Transient surface liquid in Titan's polar regions from cassini. Icarus 211, 655-671 (2011).

21. Hofgartner, J. D. et al. Titan's "magic islands": transient features in a hydrocarbon sea. Icarus 271, 338-349 (2016).

22. Le Gall, A. et al. Composition, seasonal change and bathymetry of Ligeia Mare, Titan, derived from its microwave thermal emission. J. Geophys. Res. Planets 121, 233-251 (2016).

23. Janssen, M. A. et al. Titan's surface at $2.18-\mathrm{cm}$ wavelength imaged by the Cassini RADAR radiometer: results and interpretations through the first ten years of observation. Icarus 270, 443-459 (2016).

24. Turtle, E. P. et al. Titan's meteorology over the Cassini mission: evidence for extensive subsurface methane reservoirs. Geophys. Res. Lett. 45, 5320-5328 (2018).

25. Aharonson, O. et al. An asymmetric distribution of lakes on Titan as a possible consequence of orbital forcing. Nat. Geosci. 2, 851-854 (2009).

26. Dhingra, R. D. et al. Observational evidence for summer rainfall at Titan's north pole. Geophys. Res. Lett. 46, 1205-1212 (2019).

27. Cordier, D. et al. Structure of Titan's evaporites. Icarus 270, 41-56 (2016).

28. MacKenzie, S. M. \& Barnes, J. W. Compositional similarities and distinctions between Titan's evaporitic terrains. Astrophys. J. 821, 17 (2016).

29. Mitchell, K. L., Malaska, M. J., Horvath, D. G. \& Andrews-Hanna, J. C. Karstic processes on Earth and Titan. In 45th Lunar Planet. Sci. Conf. 2371 (LPI, 2008).

30. Lorenz, R. D. \& Lunine, J. I. Erosion on Titan: past and present. Icarus 122, 79-91 (1996).

31. Malaska, M. J. \& Hodyss, R. Dissolution of benzene, naphthalene, and biphenyl in a simulated Titan lake. Icarus 242, 74-81 (2014).

32. Glein, C. R. \& Shock, E. L. A geochemical model of non-ideal solutions in the methane-ethane-propane-nitrogen-acetylene system on Titan. Geochim. Cosmochim. Acta 115, 217-240 (2013).

33. Lorenz, R. D. The flushing of Ligeia: composition variations across Titan's seas in a simple hydrological model. Geophys. Res. Lett. 41, 5764-5770 (2014).

34. Choukroun, M. \& Sotin, C. Is Titan's shape caused by its meteorology and carbon cycle? Geophys. Res. Lett. 39, L04201 (2012).

35. Alberti, G., Festa, L., Papa, C. \& Vingione, G. A waveform model for near-nadir radar altimetry applied to the Cassini mission to Titan. IEEE Trans. Geosci. Remote Sens. 47, 2252-2261 (2009).

36. Bucciarelli, T. et al. Tracking algorithms in radar altimetry. In Int. Geosci. Remote Sensing Symp. (IGARSS'88) Vol. 2, 973-976 (IEEE, 1988).

37. Mastrogiuseppe, $M$. et al. Titan dune heights retrieval by using Cassini radar altimeter. Icarus 230, 336-354 (2014).

38. Born, M. \& Wolf, E. Principles of Optics: Electromagnetic Theory of Propagation, Interference and Diffraction of Light 7 th edn (Cambridge Univ. Press, Cambridge, 1999).

39. Zhang, Z. et al. Dielectric properties of the Martian south polar layered deposits: MARSIS data inversion using Bayesian inference and genetic algorithm. J. Geophys. Res. Planets 113, 5004 (2008).

40. Fung, A. K. \& Eom, H. J. Coherent scattering of a spherical wave from an irregular surface. IEEE Trans. Antennas Propag. 31, 68-72 (1983). 
41. Picardi, G., Seu, R., Coradini, A., Zampolini, E. \& Ciaffone, A. The radar system for the exploration of Titan. Il Nuovo Cimento C 15, 1149-1161 (1992).

\section{Acknowledgements}

M.M. and R.S. acknowledge support from Italian Space Agency (ASI) grant 2014041-R.0.; M.M., A.G.H. and V.P. acknowledge support from NASA CDAP grant NNX15AH10G; J.I.L. is grateful for the ministrations of the Cassini mission in supporting his research. R.L. acknowledges the support of NASA OPR Grant NNX13AK97G. We appreciate the efforts of the Cassini TOST (Titan Orbiter Science Team) and RADAR Team in planning and executing these observations.

\section{Author contributions}

M.M. led the data analysis, conceived the main conceptual ideas and wrote the manuscript. V.P. made a significant contribution to the analysis and interpretation of data, performed some of the numerical calculations, contributed to the writing of the manuscript and prepared figures. J.I.L. participated in the calculations of the lake compositions and co-wrote the interpretation in terms of geological mechanisms. A.G.H. and R.L. participated in the interpretation of geological mechanism, contributed to drafting the article and revising it for intellectual content. R.S. and G.M. contributed to data analysis and interpretation and contributed to drafting the article.

\section{Competing interests}

The authors declare no competing interests.

\section{Additional information}

Supplementary information is available for this paper at https://doi.org/10.1038/ s41550-019-0714-2.

Reprints and permissions information is available at www.nature.com/reprints. Correspondence and requests for materials should be addressed to M.M.

Journal peer review information: Nature Astronomy thanks Alice Le Gall and the other anonymous reviewer(s) for their contribution to the peer review of this work.

Publisher's note: Springer Nature remains neutral with regard to jurisdictional claims in published maps and institutional affiliations.

(c) The Author(s), under exclusive licence to Springer Nature Limited 2019 